\title{
Review on palm oil contaminants related to 3-monochloropropane-1,2-diol (3- MCPD) and glycidyl esters (GE)
}

\author{
Sulin, S.N., ${ }^{*}$ Mokhtar, M.N., Mohammed, M.A.P. and Baharuddin, A.S. \\ Department of Process and Food Engineering, Faculty of Engineering, Universiti Putra Malaysia, 43400 \\ Serdang, Selangor, Malaysia.
}

Article history:

Received: 28 May 2020

Received in revised form: 22 July 2020

Accepted: 18 October 2020

Available Online: 27

December 2020

Keywords:

3-MCPD,

GE,

Oil palm contaminants,

Heat-induced food toxicants,

Refined edible oils

\begin{abstract}
The issue of food safety is a major concern in the oil palm industry as it will affect national income. 3-MCPD and GE are contaminants formed during the refining of palm oil, mainly in the deodorization step. Palm oil was reported to contain one of the highest levels of these contaminants amongst all vegetable oils. Both 3-MCPD and GE are characterized as a possible risk to human health. This review aimed to provide a comprehensive summary of the 3-MCPD and GE precursors and mitigation strategies to minimize the 3-MCPD and GE formation. Therefore, the oil palm industry should address these issues and find ways to comply with food laws, acts, regulations, and standards enforced by local and international authorities.
\end{abstract}

DOI:

https://doi.org/10.26656/fr.2017.4(S6).051

\section{Introduction}

After independence in 1957, agriculture played a significant role to bridge the gap between rural poor and urban area. Today's oil palm industry has become one of the key contributors to Malaysia's gross domestic product (GDP) around 5 - 7\% (Nambiappan et al., 2018). However, the oil palm industry does not always go well as it cannot avoid facing critique against issues such as environment, social, and health. Even though the negative campaign is not new, but current action led by the west influenced the oil palm economic performance in Malaysia.

3-Monochloropropanediol (MCPD) esters and glycidyl esters (GE) are categorized as food process contaminants, which are formed during the refining of palm oil mainly in the deodorization step. In 2016, the European Food Safety Authority (EFSA) published a report on the risk of 3-MCPD esters on human health which concluded that the free form and bound fatty acid esters of 3-MCPD caused kidney failure (EFSA, 2016). Realizing the fact that this issue must be well addressed, many researchers perform rigorous studies related to cause and mitigation methods that could be done to make sure the concentration of 3-MCPD within the allowable limit. The tolerable daily intake (TDI) for 3-MCPD is 0.8 $\mu \mathrm{g} / \mathrm{kg}$ as derived by the EFSA. Meanwhile, for the GE, $\mathrm{T} 25$ value (representing the dose corresponding to a $25 \%$ incidence of tumours) of $10.2 \mathrm{mg} / \mathrm{kg}$ bw per day for the incidence of tumours observed in rats. The panel did not set any safe level since there is sufficient evidence that $\mathrm{GE}$ is genotoxic and carcinogenic. In refined, bleached, and deodorized (RBD) palm oil, the amount of 3-MCPD esters between 0.2 and $4 \mathrm{mg} / \mathrm{kg}$ due to different raw oil quality and processing conditions (Crews et al., 2013).

Several approaches have been taken by many researchers to reduce 3-MCPD and GE in refined oil at various stages of oil production. This paper is not only to review different types of mitigation strategies to minimize 3-MCPD and GE but also to organize them into appropriate orders from the beginning, starting from the field to the milling stage up to the final stage, which is the refinement.

\section{3-MCPD and GE precursors}

Prior to the investigation on how to mitigate the formation of 3-MCPD and GE, it is important to gain some knowledge of their precursors and their formation pathways. By knowing so, the researcher can reduce or eliminate the precursors. The MCPD fatty acid esters formed when the mono-, di- and triacylglycerols (MAG, DAG, TAG) accept chloride from chlorin donor substance under high temperature (Destaillats et al., 2012a; Šmidrkal et al., 2016). There are many potential sources of chlorine such as coagulants used to treat water 
(Chung, 2018), in which water is used for the generation of strip steam during deodorization. There are inorganic chlorides present naturally in palm fruit extract such as calcium chloride, magnesium chloride, and iron [II] chloride (Nagy et al., 2011). The 3-MCPD formed in the refinery, especially during deodorization where high temperature $\left(180-260^{\circ} \mathrm{C}\right)$ was introduced as both 3MCPD and GE formed during heat-induced reactions. From 105 crude palm oils investigated, $80 \%$ of them contained no 3-MCPD esters but in refine, bleach, and deodorized (RBD) palm oil, only $1 \%$ of the samples contained 3-MCPD esters below the detection limit (Razak et al., 2012).

There were debates on the free fatty acid (FFA) role in the formation of 3-MCPD esters, whereby some researchers claimed that during deodorization, the fatty acid and sodium chloride (could be any ionic bound chloride e.g. $\mathrm{NaCl}, \mathrm{KCl}, \mathrm{TBAC}$ ) equilibrium is established and after that FFA salts and hydrogen chloride are formed (Šmidrkal et al., 2016). Also, the 3MCPD formation favours under acidic condition (Ramli et al., 2011; Šmidrkal et al., 2016). The MCPD fatty acid esters formation when the TAG, DAG, and MAG formed acyloxonium ion followed by nucleophilic attack of chloride ions (Rahn et al., 2011; Šmidrkal et al., 2016) as shown in Figure 1.

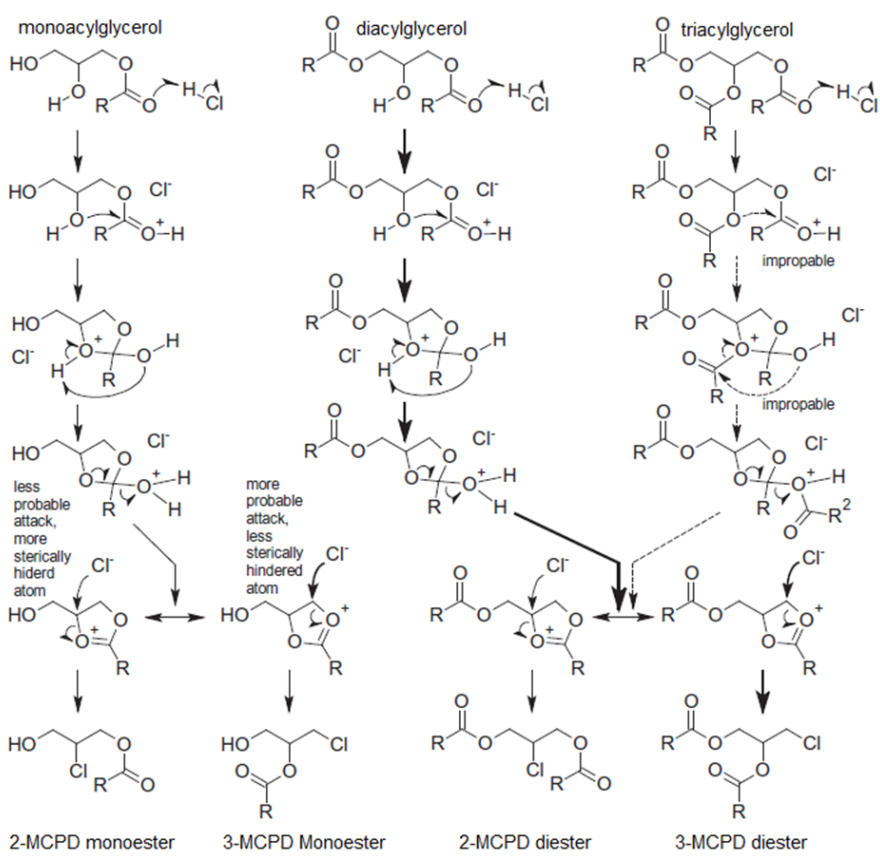

Figure 1. MCPD fatty acid esters formation mechanism (Šmidrkal et al., 2016).

Apart from the formation of intermediate such as cyclic acyloxonium ion (Figure 1) or epoxside, the pathways of 3-MCPD ester formation involves direct nucleophilic attack to the carbon either carrying ester or hydroxyl group (Rahn et al., 2011). The bidirectional transformation also could happen between glycidol and 3 -MCPD or between their esterified forms in the presence of chloride ion as in Figure 2.

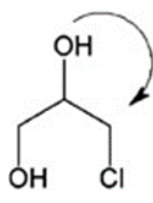

3-MCPD

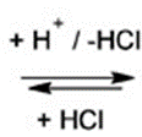

$\mathrm{HCl}$

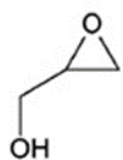

Glycidol

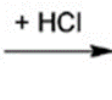<smiles>OCC(Cl)CO</smiles>

2-MCPD
Figure 2. Interconversion between 3-MCPD, GE, and 2MCPD (Rahn et al., 2011).

Partial acylglycerol such as DAG and MAG are the precursors of GE in refined oil (Cheng et al., 2017). The DAG and MAG can be formed from TAG through lipase hydrolysis or pyrolysis at high temperature (Shimizu, Vosmann and Matthäus, 2012). Unlike the MCPD esters, GE formed without the chlorine present; GE formation derived from intramolecular rearrangement through charge migration and different from each other depending on either the nature of the intermediate or the leaving group (Rahn et al., 2011; Destaillats et al., 2012b; Cheng et al., 2017). Cyclic acyloxonium ion, a well-known active intermediate in organic chemistry, may also represent in the formation of GE (Weißhaar et al., 2010). At the temperature range $180-230^{\circ} \mathrm{C}$, only small content of GE detected but above $230^{\circ} \mathrm{C}$, there is a steep increment of GE content was found (Hrnčiřík et al., 2011).

MCPD esters and GE formation are results of several competitive reactions which occur simultaneously. Even there is a competition between the same group forming a number of chloropropanol (CP) types, which explains why neither partial acylglycerol nor chlorinated compound could firmly correlate with the level of MCPD ester formed upon thermal heating (Ermacora et al., 2014).

\section{Mitigation strategies to minimize the 3-MCPD and GE formation}

After understanding the precursors of 3-MCPD and GE formation, some researchers focused on how to reduce or eliminate the precursors such as removal of chlorin, partial acylglycerol, and free fatty acids (FFA). At the same time, others focused on changing the operation procedures, especially in the refining process, by introducing new steps of removing the formed MCPD esters and GE.

\subsection{Field mitigation strategies}

Several researchers related the inorganic chlorides in soils with the fertilizers used to support plant growth such as ammonium chloride and potassium chloride. 
Other than that, chloride possibly comes from the water irrigated to the farms. Both fertilizer and water will be absorbed by the plant for growth. The variation of the chloride-containing compound in the palm fruit depends on differences in the soil types, growth conditions, and genotype of the plants. So, the mitigation of MCPD esters needs as early intervention during cultivation by minimizing the use of substances such as fertilizers, pesticides, and irrigation water that have excessive amounts of chlorine-containing (Matthäus et al., 2011).

The DAG, MAG, and FFA inside the fruit will increase when the TAG inside the mesocarp is hydrolyzed by lipase enzyme which also inside the fruit mesocarp. When the fruit ripes, the exocarp becomes soft and therefore makes it easy to be attacked by the lipase enzyme. Other than ripening factors, the lipase activity also accelerated by the damage of mesocarp tissue as a result of improper handling (Sambanthamurthi et al., 2000). To minimize the FFA content, the fresh fruit bunch must be harvested before overripe with proper handling to prevent the bruise. The loose and damaged fruit should be collected for non-food purposes as it has low-quality oil. After harvesting, the fresh fruit bunches should be transported immediately to the factory for sterilization to inactivate the lipase enzyme.

\subsection{Milling mitigation strategies}

Sterilization will aid to stop the lipase activity as the enzyme inactive at high temperature which at least around $70^{\circ} \mathrm{C}$ for 40 mins within palm fruit (Shehu et al., 2019), but conventional sterilization is performed at $140^{\circ}$ $\mathrm{C}$ between 75 and 90 mins. According to Cheng et al. (2017), the sterilization temperature is better to be kept at or below $120^{\circ} \mathrm{C}$ (Cheng et al., 2017). This is due to MCPD ester can be formed at a temperature of $120^{\circ} \mathrm{C}$ and higher (Zhao et al., 2016).

The extraction of oil palm in the mill is usually done by mechanical means but Matthäus and Pudel (2014) suggested the use of a biphasic polar solvent (e.g. hexane -water) that can reduce the 3-MCPD diesters content. However, the adoption of this method will face toxicity of extracted oil and safety issues (i.e. high flammability of hexane), thus contrary to public acceptance.

Other than that, several researchers tested the forming of 3-MCPD from chlorine-containing $\mathrm{CPO}$; it was washed with water (also with solvent), and then treated at high temperature (i.e. $230-240^{\circ} \mathrm{C}$ ) to observe the formation of 3-MCPD (Matthäus et al., 2011; Craft et al., 2012). According to Matthäus et al. (2011), they found that after washing the CPO with water-ethanol of $25: 75$, showing that 3 -MCPD esters, reduce to about $30 \%$ (compared to $\mathrm{CPO}$ without washing) after the heat treatment, while the amount of GE was nearly unchanged, as shown in Figure 3. However, some drawbacks of washing the CPO using this method as it is costly, facing oil loss and emulsification properties own by phospholipids or other components lead to difficult separation.

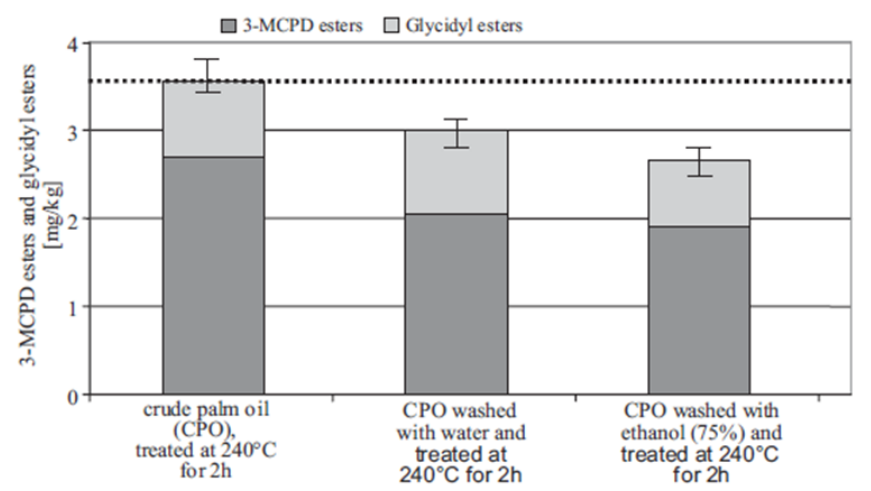

Figure 3. Effect of washing on the capability to form 3-MCPD esters and GE from $\mathrm{CPO}$ after the heat treatment (Matthäus $e t$ al., 2011)

\subsection{Refining mitigation strategies}

The purpose of refining is to prepare the oil is edible; unacceptable components such as oxidation products, FFA, phospholipids, metals, trace of pesticide, and other impurities are removed (Ramli et al., 2011). In general, the $\mathrm{CPO}$ can be refined through chemical refining process which involves four steps (i.e. degumming, neutralization, bleaching, deodorization) or via physical refining which consists of only three steps (i.e. degumming, bleaching, and deodorization). For the time being, the palm oil industry prefers physical refining because it gives advantage such as less environmental impact.

\subsubsection{Before deodorization}

Some of the researchers suggested improving the refining process in reducing the 3-MCPD and GE formation. For instance, the use of a low concentration of acid during degumming and the use of a natural type of bleaching earth instead of acidic bleaching earth (Vispute et al., 2018). Ramli et al. (2011) found that the formation of 3-MCPD ester at the highest level (up to $3.89 \mathrm{ppm}$ ) when using high dosage of phosphoric acid $0.1 \%$ (from tested range $0.012-0.1 \%$ ) with a combination of acid-activated clay. The 3-MCPD esters formation were the lowest $(0.25 \mathrm{ppm})$ when water degumming and natural bleaching clay was used. However, there is a drawback of using water degumming as it affects the oil quality due to insufficient removal of iron and phosphorus compounds. This work is suitable for using high-quality CPO. If the quality oil used is not good, it will have to be combined with another step, especially to remove the metallic impurities. 
Some researchers suggested the neutralization step by adding calcium carbonate (Vispute et al., 2018), calcium oxide (Ramli et al., 2011), alkali potassium, or sodium bicarbonate (Šmidrkal et al., 2016) to the degummed oil or during the bleaching process. On the other hand, Schurz (2010) proposed to use a high dosage of activated clay as it can absorb some of the 3-MCPD ester precursors from the oil. Besides, natural clay is recommended for the bleaching process, as mentioned before. However, natural bleaching earth may bring a negative effect on the colour of the oil. Chemical refining is seemed to be more attractive in the effort to reduce the 3-MCPD and GE as neutralization step offers pre-removal of FFA (Vispute et al., 2018), thus improves the $\mathrm{pH}$ of the oil before deodorization.

The idea of adding additives in the bleached oil can prevent 3-MCPD formation; additives compete with precursors (e.g. chlorine-donating agent) in the reaction before stripping off during deodorization. Craft et al. (2012) added alcohol (e.g. ethanol, 2-propanol glycerol) to bleached palm oil, producing volatile chlorinated compounds that can be evaporated during deodorization, thus reducing the 3-MCPD esters.

Bertoli et al. (2011) described the effect of contacting carboxymethyl cellulose or cation exchange resin with oil resulting in a reduction of 3-MCPD content (comprises an amount of $1000 \mu \mathrm{g}$ or less per $\mathrm{kg}$ of oil) after contacting time of $1 \mathrm{hr}$ at $60^{\circ} \mathrm{C}$ in a double jacketed glass reactor. The CPO was bleached using at least three absorbents such as $0.5 \%$ trisyl silica, $2 \%$ bleaching earth, and a suitable amount of ion exchange resin or carboxymethyl cellulose depending on the ratio of oil to resin. After the resin or carboxymethyl cellulose was removed, the bleached palm oil was deodorized using steam or nitrogen gas.

A patent provided by Zieverink et al. (2011)

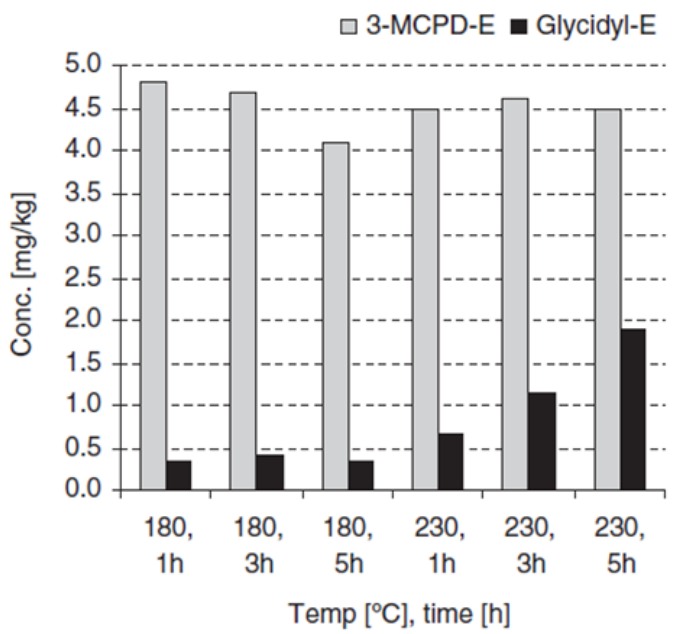

Figure 4. Formation of 3-MCPD esters and GE in palm oil (neutralized-bleached) after deodorizing at different times and temperatures in chemical refining (Hrnčiřík et al., 2011) discusses the fractionation of oil prior to deodorization whereby the solid high melting fraction (stearin) is separated from a liquid low melting fraction (olein). The deodorized palm oil fraction having 3-MCPD ester content of less than $1 \mathrm{ppm}$. However, there is no clear explanation of why fractionation can reduce MCPD esters.

\subsubsection{Deodorization}

According to Hrnčiŕík et al. (2011), the deodorization conditions such as temperature (i.e. $180^{\circ} \mathrm{C}$ $-230^{\circ} \mathrm{C}$ ) and residence time (i.e. $1-5 \mathrm{hrs}$ ), affected the level of GE but not to 3-MCPD esters within neutralizedbleached and bleached palm oil as shown in Figure 4 and Figure 5, respectively. Regardless of the deodorization conditions, the concentration of the 3-MCPD ester was more or less similar $(3.5-4.7 \mathrm{mg} / \mathrm{kg})$. On the contrary, GE concentration increased up to $2.2 \mathrm{mg} / \mathrm{kg}$ when the deodorization temperature at $230^{\circ} \mathrm{C}$ as shown in Figure 5. The results also show that lower deodorization temperature, $180^{\circ} \mathrm{C}$, lower GE level was observed. However, it was not sufficient to remove FFA from the oil in which only $20 \%$ removal even deodorized for 5 hrs.

Dual deodorization had been discussed by Matthäus et al. (2014), to reduce the 3-MCPD esters and GE. The process is a combination of applying a longer deodorization time at lower temperature (i.e. 120 mins, $200^{\circ} \mathrm{C}$ ), then followed by a shorter deodorization time at higher temperature (i.e. 5 mins, $250^{\circ} \mathrm{C}$ ) or vice versa as stated in Figure 6. GE can be distilled or degraded at a higher temperature of $250-290^{\circ} \mathrm{C}$ or at a lower temperature of $200^{\circ} \mathrm{C}$ with longer deodorization time (e.g. 2 hrs), which is discussed by Craft et al. (2012).

Pudel et al. (2016) proposed a short path distillation instead of conventional deodorization. They reported that

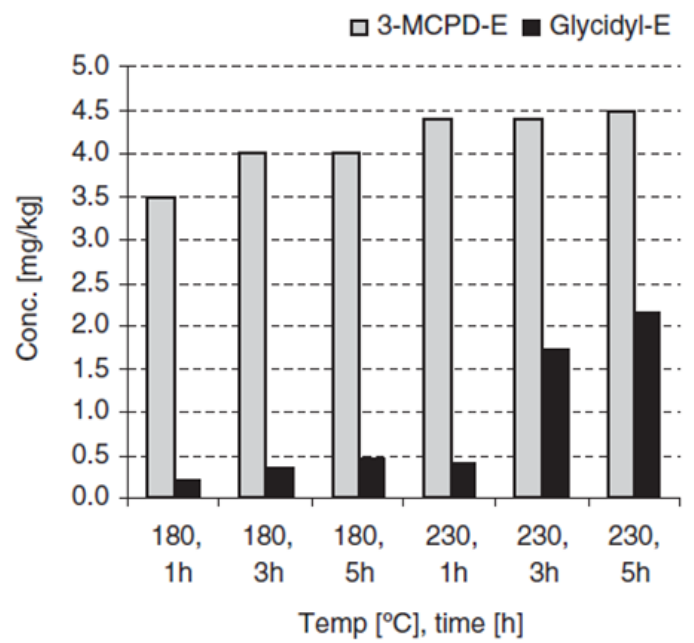

Figure 5. Formation of 3-MCPD esters and GE in palm oil (bleached) after deodorizing at different times and temperatures in physical refining (Hrnčiríík et al., 2011). 
for the different variables such as condenser temperatures, evaporator temperatures, stirrer speeds, and pump frequencies, there was no 3-MCPD ester was detected in any of the samples, while the level for GE at the limit of detection, $0.7 \mathrm{mg} / \mathrm{kg}$. The optimum conditions in their works were condenser temperature at $60^{\circ} \mathrm{C}$, evaporator temperature at $170^{\circ} \mathrm{C}$, stirrer speed at $100 \mathrm{r} / \mathrm{min}$, and pump frequency at $20 \mathrm{~Hz}$. Matthäus et al. (2014) explained that short path distillation is one of the thermal separation techniques that taking advantage of high vacuum pressure (0.001-1 mbar) to lower the boiling point of substance, thus will facilitate the evaporation of undesired components.

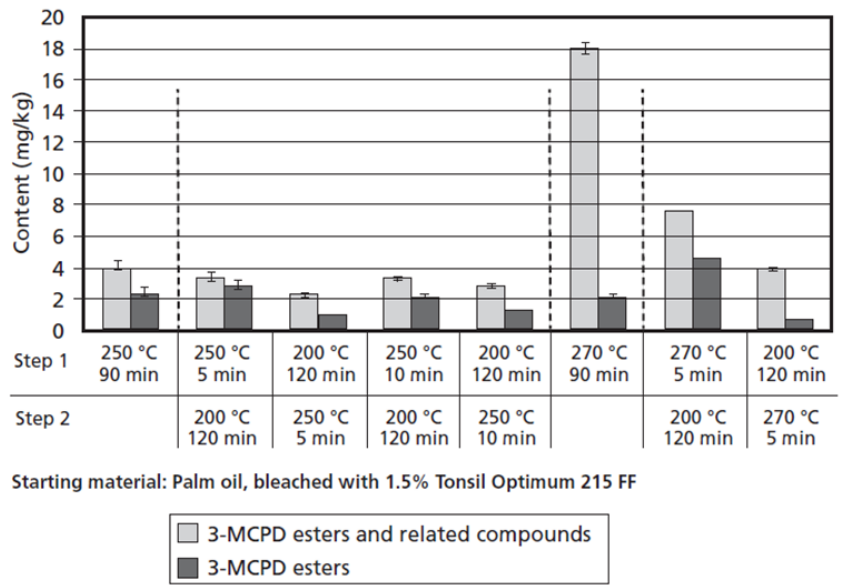

Figure 6. Effect of conventional and dual deodorization on 3MCPD esters and related compounds formation (Matthäus et al., 2014).

The presence of GE in RBD oil is determined by the rate of formation of GE and the rate of stripping of GE into the distilled phase. So, by knowing this, the refinery conditions can be modified by optimizing the parameters used (e.g. stripping steam rate, temperature, and pressure) in the steam distillation process during deodorization (Özdikicierler et al., 2015). The authors said that there is significant interaction between stripping steam rate and temperature to the GE formation in their experiment.

Some researchers proposed the different types of stripping agents such as inert gas (Bertoli and Cauville, 2011) or acid solution (Matthäus et al., 2011). When using an inert gas (i.e. nitrogen) as a stripping agent, they found that it will limit the formation of bound MCPD in oil as in Table 1. Bertoli et al. (2011) suggested the temperature of deodorization is between $140^{\circ} \mathrm{C}$ and $180^{\circ} \mathrm{C}$, and under vacuum less than 50 mbar (preferentially less than 10 mbar). In addition, Siew et al. (2012) presumed that the inert gas prevents direct contact of chloro-compound with the oil. According to Matthäus et al. (2011), they replaced water with formic acid to generate strip steam and reduction almost $35 \%$ of GE in the RBD oil using a high concentration of formic acid due to GE are not stable under acidic conditions.

Table 1. Comparison of the 3-MCPD content in bleached palm oil stripped with steam and nitrogen (Bertoli et al. 2011).

\begin{tabular}{cc}
\hline Stripping medium & $3-\mathrm{MCPD} \mu \mathrm{g} / \mathrm{kg}$ \\
\hline $1^{\text {st }}$ steam trial & 1340 \\
$2^{\text {nd }}$ steam trial & 1230 \\
$1^{\text {st }}$ nitrogen trial & 780 \\
$2^{\text {nd }}$ nitrogen trial & 710 \\
\hline
\end{tabular}

\subsection{Post refining strategies}

\subsubsection{3-MCPD esters and GE removal from $R B D$ oil}

The 3-MCPD and GE can be removed from RBD oil by several methods such as physical adsorption, chemical degradation, and enzymatic reaction. Physical adsorption is mean to remove the 3-MCPD and GE by adsorbents such as activated carbon, magnesium silicate, zeolite, and activated bleaching earth without damaging their molecule structure by taking advantage of the fact that 3-MCPD esters and GE have different polarity from the oil. Strijowski et al. (2011) described that calcinated zeolite and synthetic magnesium silicate are possible absorbents in reducing polar materials such as DAG, MAG as well as the 3-MCPD esters and GE, with different transposition rates from both adsorption materials. As they found out that calcinated zeolite and synthetic magnesium silicate reached a maximum total reduction effected at different temperatures and times.

Shimizu et al. (2012) had used the acid-activated bleach earth (ABE) on RBD oil. They found out that rather than adsorption, there is a transformation of GE into glycerol mono-palmitate, glycerol palmitate oleate, and glycerol dipalmitate. This happens because of the GE that absorbed by ABE undergoes a molecular ringopening reaction. The last method to be discussed under this topic is the reduction of 3-MCPD and GE using the enzymatic treatment. In the aqueous system, the 3MCPD converted to glycerol using enzyme consists of halohydrin dehalogenase from Arthrobacter sp. AD2 and an epoxide hydrolase from Agrobacterium radiobacter AD1 (Bornscheuer and Hesseler, 2010). According to them, Candida antartica lipase A also can convert 3MCPD-esters to harmless glycerol in a biphasic system.

\subsubsection{Storage}

Matthäus et al. (2016) reported that the concentration of GE decrease when the oil stored at low temperature $\left(5-15^{\circ} \mathrm{C}\right)$, as the crystallization process delivers enough energy to cleave the epoxy bonding of the GE. The degradation rate of GE per month at different temperatures is shown in Table 2. So, it is important in the production and in the distribution line to keep the oil in low-temperature storage or during 
transportation as the GE decreasing.

Table 2. Degradation of GE per month at different temperatures (Matthäus et al. 2016).

\begin{tabular}{cc}
\hline Temperature $\left({ }^{\circ} \mathrm{C}\right)$ & Decrease glycidyl ester/month $(\mathrm{mg} / \mathrm{kg})$ \\
\hline 20 & 0.0 \\
15 & 0.2 \\
10 & 0.3 \\
5 & 0.4 \\
-20 & 0.1 \\
\hline
\end{tabular}

\section{Conclusion}

The formation of 3-MCPD esters and GE greatly affected by the precursors such as chloride, DAG, MAG, and parameters such as temperature and $\mathrm{pH}$. Build up some of the precursors should be avoided and eliminated. The mitigation step should be implemented for the whole chain of oil palm productions. Some of the mitigation procedures are expensive, thus become a turning point for many refiners to implement those approaches. The best practice scenario that can be adopted base on this review consists of several steps. The first step is to remove the precursors during the milling stage before extraction of the oil (e.g. use free-chlorine water, washing fruit from any pesticide or fertilizer residue, etc.), followed by the second step of selecting appropriate method and conditions during degumming. The final stage is to improve deodorization at optimal temperature and stripping rate; to minimize unwanted reactions and maximize the removal of 3-MCPD and GE.

\section{Conflict of interest}

The authors declare no conflict of interest.

\section{Acknowledgments}

The research work is supported by the Universiti Putra Malaysia grant (Putra Grant - 9564100).

\section{References}

Bertoli, C., Cauville, F. and Schoonman, A.J.H. (2011). A deoodorized edible oil or fat with low levels of bound MCPD and process of making by carbozymethyl cellulose and/or resin purification. Patent No WO2011009841A1. Geneva, Switzerland: World Intellectual Property Organization.

Bertoli, C. and Cauville, F. (2011). A deodorized edible oil or fat with low levels of bound MCPD and process of making using an inert gas. Patent No WO2011009843A1. Geneva, Switzerland: World Intellectual Property Organization.

Bornscheuer, U.T. and Hesseler, M. (2010). Enzymatic removal of 3-monochloro-1,2-propanediol (3MCPD) and its esters from oils. European Journal of Lipid Science Technology, 112(5), 552-556. https:// doi.org/10.1002/ejlt.200900245

Cheng, W.W., Liu, G.Q., Wang, L.Q. and Liu, Z.S. (2017). Glycidyl fatty acid esters in refined edible oils: A review on formation, occurrence, analysis, and elimination methods. Comprehensive Reviews in Food Science and Food Safety, 16(2), 263-281. https://doi.org/10.1111/1541-4337.12251

Chung, Y.K.A. (2018). Crude palm oil de-chlorination. Palm Oil Engineering Buletin, 128, 51-57.

Craft, B.D., Nagy, K., Seefelder, W., Dubois, M. and Destaillats, F. (2012). Glycidyl esters in refined palm (Elaeis guineensis) oil and related fractions. Part II: Practical recommendations for effective mitigation. Food Chemistry, 132(1),73-9. https:// doi.org/10.1016/j.foodchem.2011.10.034

Crews, C., Chiodini, A., Granvogl, M., Hamlet, C., Hrnčiřík, K., Kuhlmann, J., Lampen, A., Scholz, G., Weisshaar, R., Wenzl, P.T., Jasti, R. and Seefelder, W. (2013). Analytical approaches for MCPD esters and glycidyl esters in food and biological samples: A review and future perspectives. Food Additives and Contaminants: Part A, 30(1), 11-45. https:// doi.org/10.1080/19440049.2012.720385

Destaillats, F., Craft, B.D., Sandoz, L. and Nagy, K. (2012a). Formation mechanisms of monochloropropanediol (MCPD) fatty acid diesters in refined palm (Elaeis guineensis) oil and related fractions. Food Additives and Contaminants Part A Chemical Analysis control Expo Risk Assessment, 29 (1), 29-37. https:// doi.org/10.1080/19440049.2011.633493

Destaillats, F., Craft, B.D., Dubois, M. and Nagy, K. (2012b). Glycidyl esters in refined palm (Elaeis guineensis) oil and related fractions. Part I: Formation mechanism. Food Chemistry, 131(4),1391 $-1398$ https://doi.org/10.1016/ j.foodchem.2011.10.006

EFSA. (2016). Glycidyl esters and 3-MCPD in vegetable oil and food. Chemicals in food: Overview of selected data collection. European Food Safety Authority Journal, 14, 30-37.

Ermacora, A. and Hrncirik K. (2014). Influence of oil composition on the formation of fatty acid esters of 2 -chloropropane-1,3-diol (2-MCPD) and 3chloropropane-1,2-diol (3-MCPD) under conditions simulating oil refining. Food Chemistry, 161, 383389. https://doi.org/10.1016/j.foodchem.2014.03.130

Hrnčiř́ik, K. and Van Duijn, G. (2011). An initial study on the formation of 3-MCPD esters during oil 
refining. European Journal of Lipid Science Technology, 113(3), 374-379. https:// doi.org/10.1002/ejlt.201000317

Matthäus, B., Pudel, F., Fehling, P., Vosmann, K. and Freudenstein, A. (2011). Strategies for the reduction of 3 MCPD esters and related compounds in vegetable oils. European Journal Lipid Science, 113 (3), 380-386. https://doi.org/10.1002/ejlt.201000300

Matthäus, B. and Pudel, F. (2014). 2-Mitigation of MCPD and Glycidyl esters in edible oils. In MacMahon, S. (Ed.) Processing contaminants in edible oils: MCPD and Glycidyl Esters, p. 23 - 5.. USA: Academic press and AOCS press. https:// doi.org/10.1016/B978-0-9888565-0-9.50007-5

Matthäus, B., Vosmann, K., Weitkamp, P., Grundmann, D. and Kersting, H.J. (2016). Degradation of glycidyl esters in RBD palm oil as a function of storage conditions. European Journal of Lipid Science Technology, 118(3), 418-424. https:// doi.org/10.1002/ejlt.201500312

Nagy, K., Sandoz, L., Craft, B.D. and Destaillats, F. (2011). Mass-defect filtering of isotope signatures to reveal the source of chlorinated palm oil contaminants. Food Additives and Contaminants Part A Chemical Analysis Control Expo Risk Assess, 28(11), 1492-1500. https:// doi.org/10.1080/19440049.2011.618467

Nambiappan B., Ismail, A., Hashim, N., Ismail, N., Shahari, D.N., Nik Idris, N.A., Omar, N., Mohamed Salleh, K., Mohd Hassan, N.A. and Kushairi, A. (2018). Malaysia: 100 years of resilient palm oil economic performance. Journal of Oil Palm Research, 30(1), 13-25. https://doi.org/10.21894/ jopr.2018.0014

Özdikicierler, O., Yemişçioğlu, F. and Gümüşkesen, A.S. (2016). Effects of process parameters on 3MCPD and glycidyl ester formation during steam distillation of olive oil and olive pomace oil. European Food Resources Technology, 242, 805813. https://doi.org/10.1007/s00217-015-2587-7

Pudel, F., Benecke, P., Vosmann, K. and Matthäus, B. (2016). 3-MCPD- and glycidyl esters can be mitigated in vegetable oils by use of short path distillation. European Journal Lipid Science Technology, 118(3), 396-405. https:// doi.org/10.1002/ejlt.201500095

Rahn, A.K.K. and Yaylayan, V.A. (2011). What do we know about the molecular mechanism of 3-MCPD ester formation? European Journal of Lipid Science and Technology, 113(3), 323-329. https:// doi.org/10.1002/ejlt.201000310

Ramli, M.R., Siew, W.L., Ibrahim, N.A., Hussein, R.,
Kuntom, A. and Razak, R.A.A. (2011). Effects of degumming and bleaching on 3-MCPD esters formation during physical refining. Journal of the American Oil Chemists' Society, 88(11), 1839-1844. https://doi.org/10.1007/s11746-011-1858-0

Sambanthamurthi, R., Sundram, K. and Tan, Y.A. (2000). Chemistry and biochemistry of palm oil. Progress in Lipid Resources, 39(6), 507-558. https:// doi.org/10.1016/S0163-7827(00)00015-1

Schurz, K. (2010). Method for reducing the 3-MCPD content in refined vegetable oils. Patent No WO2010063450A1. Geneva, Switzerland: World Intellectual Property Organization.

Shehu, U.E., Mokhtar, M.N., Mohd Nor, M.Z., Baharuddin, A.S. and Mat Nawi, N. (2019). A Study on the use of water as a medium for the thermal inactivation of endogenous lipase in oil of palm fruit. Energies, 12(20), 3981. https://doi.org/10.3390/ en12203981

Shimizu, M., Vosmann, K. and Matthäus, B. (2012). Generation of 3-monochloro-1,2-propanediol and related materials from tri-, di-, and monoolein at deodorization temperature. European Journal of Lipid Science and Technology, 114(11), 268-1273. https://doi.org/10.1002/ejlt.201200078

Shimizu, M., Moriwaki, J., Shiiba, D., Nohara, N., Kudo, N. and Katsuragi, Y. (2012). Elimination of glycidyl palmitate in diolein by treatment with activated bleaching earth. Journal Oleochemical Science, 61 (1), 23-28. https://doi.org/10.5650/jos.61.23

Siew, W.L., Kuntom, A., Ibrahim, N.A., Ramli, M.R. and Abd. Razak., R.A. (2012). The possible mitigation procedures for the reduction of the formation of chloropropanol esters and related compounds. Palm Oil Development, 57, 21-27.

Šmidrkal, J., Tesařová, M., Hrádková, Berčíková, I., Adamčíková, A. and Filip. V. (2016). Mechanism of formation of 3-chloropropan-1,2-diol (3-MCPD) esters under conditions of the vegetable oil refining. Food Chemistry, 211, 124-129. https:// doi.org/10.1016/j.foodchem.2016.05.039

Strijowski, U., Heinz, V. and Franke, K. (2011). Removal of 3-mcpd esters and related substances after refining by adsorbent material. European Journal Lipid Science Technology, 113(3), 387-392. https://doi.org/10.1002/ejlt.201000323

Vispute, P. and Dabhade, S. (2018). Refining of palm oil: A review on palm oil refining process, 3-MCPD esters in refined palm oil, and possible reduction tactics for 3-MCPD esters. International Journal of Agricultural Engineering, 11, 81-85. https:// doi.org/10.15740/HAS/IJAE/11.Sp.Issue/81-85 
Weißhaar, R. and Perz, R. (2010). Fatty acid esters of glycidol in refined fats and oils. European Journal Lipid Science Technology, 112(2), 158-65. https:// doi.org/10.1002/ejlt.200900137

Zhao, Y., Zhang, Y., Zhang, Z., Liu, J., Wang, Y.L., Gao, B., Niu. Y., Sun, X. and Yu, L. (2016). Formation of 3-mcpd fatty acid esters from monostearoyl glycerol and the thermal stability of 3mopd monoesters. Journal Agriculture Food Chemistry, 64(46), 8918-8926. https:// doi.org/10.1021/acs.jafc.6b04048

Zieverink, M.M.P, De Ruiter, G.A., Abdul Lapit, R., Al Krishnan, A. and Hashim, K. (2011). Process for manufacturing palm oil fractions containing virtually no 3-monochloropropanediol fatty acid esters. Patent No. WO2011002275A1. Geneva, Switzerland: World Intellectual Property Organization. 